\title{
Research on How Lens Position of the Optical System is Influencing the Mechanical Characteristics of the Metallic Parts Made by Selective Laser Melting Equipment
}

\author{
Razvan Pacurar ${ }^{1, a}$ and Petru Berce ${ }^{1, b}$ \\ ${ }^{1}$ B-dul Muncii no.103-105, 400641, Cluj-Napoca, Romania

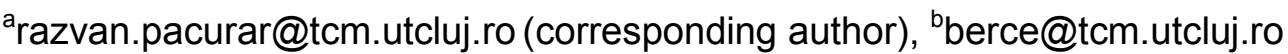

\begin{abstract}
Keywords: Additive Manufacturing; Selective Laser Melting; MCP Realizer II SLM 250; Stainless Steel 316L, Mechanical Characteristics; Finite Element Analysis, Lens Position.
\end{abstract}

\begin{abstract}
The Selective Laser Melting (SLM) is one of the most important Additive Manufacturing (AM) technologies that have been developed in the last few years, with applications in different domains, starting with the industrial engineering and ending with biomedical industry, as well. According to the type of the application (industrial or medical), the challenges and requirements related to this modern technology are different, regarding the mechanical properties of the manufactured parts. The article presents the theoretical and experimental research that was made by the authors in order to improve the mechanical characteristics of the metallic parts manufactured by using the Selective Laser Melting (SLM) technology. Finite element analysis method has been successfully used in order to study the connection between the density of the material and the fracture strength of several samples that were manufactured from Stainless Steel 316L material, at the Technical University of Cluj-Napoca, using the MCP Realizer II SLM 250 equipment. The experimental results that have been obtained by the authors have finally proved that there is a very strong connection between the lens position of the optical system and the resulted porosity of the parts manufactured by using the SLM machine.
\end{abstract}

\section{Introduction}

The Selective Laser Melting (SLM) technology is one of the most representatives Additive Manufacturing (AM) techniques that were developed in the last few years [1]. It is well known the Selective Laser Melting basic principle of manufacturing metallic parts that uses a laser source directed through an optical system onto a base plate, in order to melt the powder and weld the metallic grains together according to the cross section of the 3D model, process that it is repeated layer by layer, until the part is finished $[2,3]$. But even if the process sounds easy in theory, the things are looking different in practice. There are a lot of technological parameters that needs to be controlled within the Selective Laser Melting process, so as the manufactured part will have the optimum mechanical properties at the end [4]. The range of materials and the range of applications were significantly increased in the last years, on one hand, due to the increasing of the equipment performances, and on the other hand, due to the high interest shown by a lot of important companies and research institutes in the world, in the field of auto-motive, aerospace or biomedical industry [5, 6]. The research developed regarding the Selective Laser Melting technology is differently oriented in the world, due to the fact that, the requests are different according to the type of the application we are referring to $[7,8]$. If we refer to the medical field for example, the desired structures will be designed as having a high level of porosity, in order to be easily mixed with other biocompatible materials, with similar properties as the human bone, at the end [9]. If we refer to the industrial field instead, the requests regarding the mechanical properties of a manufactured part by using the Selective Laser Melting technology would be as having a fully-dense structure, at the end [10]. The presented work investigates how the mechanical characteristics (porosity, density, fracture strength) of the metallic parts manufactured by Selective Laser Melting are influenced by the lens position adjustment within the optical system of the machine. 


\section{Materials and methods}

In order to study the influence of the lens position over the material structure (density) of the metallic parts made by SLM, a sample as the one presented in Figure 1, has been designed with SolidWorks software, in order to be manufactured by Stainless Steel 316L material, using different lens positions of the MCP Realizer II SLM 250 machine, from the Technical University of ClujNapoca.
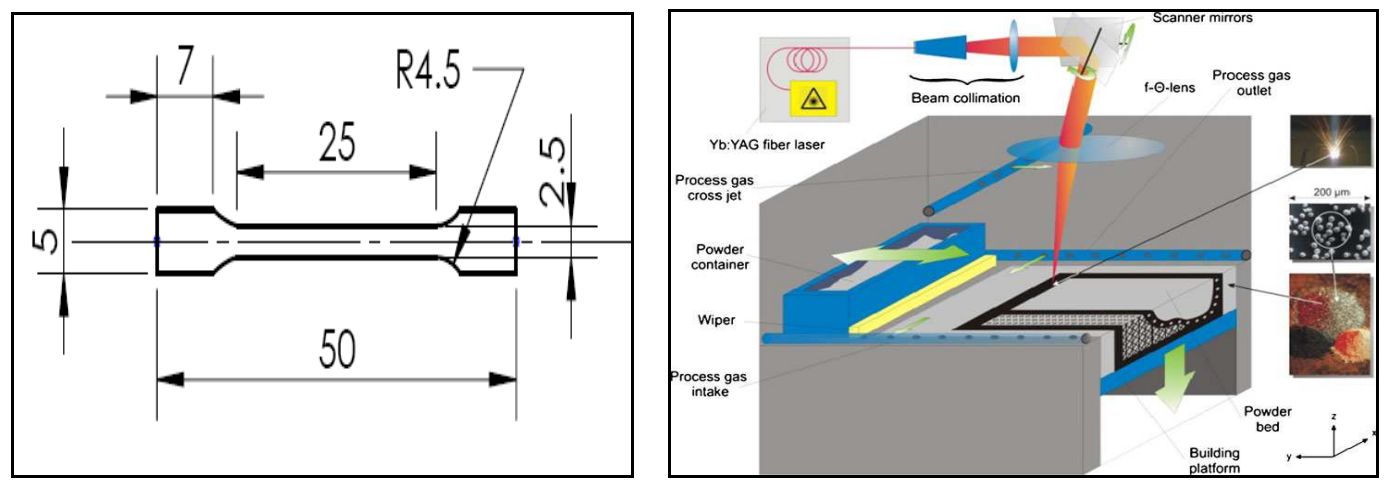

Fig.1. Sample designed to be manufactured by SLM at the Technical University of Cluj-Napoca, using different lens positions of the the MCP Realizer II SLM 250 machine

There are few technological parameters, which were maintained constant during the made experiments, as illustrated in Table 1. Meantime, it was an important difference used to set-up the made experiments, related to the lens position parameter of the 15 manufactured samples to be realized using the SLM machine, as presented in Table 2.

Table 1. Technological parameters used within the SLM process of samples

\begin{tabular}{|c|c|c|c|}
\hline Laser power [W] & $\begin{array}{c}\text { Scanning speed } \\
{[\mathrm{m} / \mathrm{s}]}\end{array}$ & $\begin{array}{c}\text { Hatching distance } \\
(\mathrm{X} \& \mathrm{Y})[\mathrm{mm}]\end{array}$ & $\begin{array}{c}\text { Layer thickness } \\
{[\mu \mathrm{m}]}\end{array}$ \\
\hline 200 & 0.4 & 0.12 & 50 \\
\hline
\end{tabular}

Table 2. Lens position used within the SLM process

\begin{tabular}{|c|c|}
\hline \multirow{2}{*}{$\begin{array}{c}\text { Sample } \\
\text { no. }\end{array}$} & \begin{tabular}{c} 
Lens Position $[\mu \mathrm{m}]$ \\
\cline { 2 - 2 }
\end{tabular} \\
$\begin{array}{c}\text { Hatch Solid and Fill } \\
\text { Contour }\end{array}$ \\
\hline 1 & -70 \\
\hline 2 & -60 \\
\hline 3 & -50 \\
\hline 4 & -40 \\
\hline 5 & -30 \\
\hline 6 & -20 \\
\hline 7 & -10 \\
\hline 8 & 0 \\
\hline
\end{tabular}

\begin{tabular}{|c|c|}
\hline \multirow{2}{*}{$\begin{array}{c}\text { Sample } \\
\text { no. }\end{array}$} & Lens Position $[\mu \mathrm{m}]$ \\
\hline & $\begin{array}{l}\text { Hatch Solid and Fill } \\
\text { Contour }\end{array}$ \\
\hline 9 & 10 \\
\hline 10 & 20 \\
\hline 11 & 30 \\
\hline 12 & 40 \\
\hline 13 & 50 \\
\hline 14 & 60 \\
\hline 15 & 70 \\
\hline
\end{tabular}

The lens position scanning system of every layer (numerically controlled on $\mathrm{X}$ and $\mathrm{Y}$-axes) it is composed by an ytterbium laser fiber source that emits a laser beam and the optical system composed by the scanning mirrors and lenses that are needed in order to focus the laser beam onto the building platform of the SLM machine at the end, as illustrated in Figure 1.

The calibration procedure of the machine is referring actually to the position adjustment of the focusing lens, in correlation with the X-Y scanning mirrors, so as the focus distance will be the optimum one at the end. If the focusing lens will not be in the right position, than the focus plane 
will be situated above or below the building platform plane. This will have critical consequences over the internal structure of the manufactured part and its mechanical properties at the end, as it was demonstrated by the experimental results obtained in the made research.

As related to the lens position that has been varied in the case of manufactured sample (see Table 2), it is also important to notice that the same values of lens positions were used, both, in the case of hatching the solid material and filling the section contour, as the scanning strategy for the SLM machine. By setting-up the experiment in this way, it is expected that the resulted porosity in the material internal structure will be caused by the lens position influence within the optical system of the SLM machine, exclusively. The lens position has been changed during scanning procedure, from a sample to another, with the indicated values, as compared to the starting position (the current position which in initial case has been considered as being set to zero).

After the samples were manufactured by SLM, in order to analyze how lens position has been affected the internal structure of the material and the quality surface on the contour, scanning electron microscopy method has been used for a visual investigation of the part microstructures. The visual investigation was sufficient in this case, due to the resulted defects that were clearly visible at a microscopic level. Meantime, in order to have a more clear appreciation regarding the porosity and density of the material, there were made also supplementary investigations, basically simple in principle. By using an analytic balance and a graduated cylinder, it was easy to determine the density of material. By having the volume of the sample, determined using the law of Archimedes, the porosity of the sample was also easy to be determined, using the formula (1):

$$
P=\frac{\Delta V}{V} * 100 \quad[\%]
$$

where:

$\mathrm{P}$ - porosity of the sample [\%]

$\Delta \mathrm{V}-$ volume of pores within the structure of the sample $\left[\mathrm{cm}^{3}\right]$.

The volume of the pores within the sample's structure can be determined using formula (2):

$$
\Delta V=V-V o\left[\mathrm{~cm}^{3}\right]
$$

where:

$\mathrm{V}_{0}$ - volume of the sample, determined for the ideal case of the material $\left[\mathrm{cm}^{3}\right]$. In order to determine the volume $\mathrm{V}_{0}$, the density of the material was considered, as specified from the Stainless Steel $316 \mathrm{~L}$ material producer $\left(\rho=8\left[\mathrm{~g} / \mathrm{cm}^{3}\right)[11]\right.$.

Finally, in order to estimate how the material density variation is influencing the fracture strength of the parts made by Selective Laser Melting technology, finite element method has been used, in two cases, by taking into account the lowest and the highest values of densities obtained within made experiments.

According to all made experiments, few recommendations were stated at the end related to the lens position adjustment within the optical system of the SLM machine, so as the part would have a maximum strength at the end.

\section{Experiments}

15 samples as the one presented in Figure 1 were successfully manufactured by using the MCP Realizer II SLM 250 machine from the Technical University of Cluj-Napoca (illustrated in Figure 2), by taking into account the technological parameters presented in Table 1 and Table 2. 


\section{Innovation for Sustainable Development}
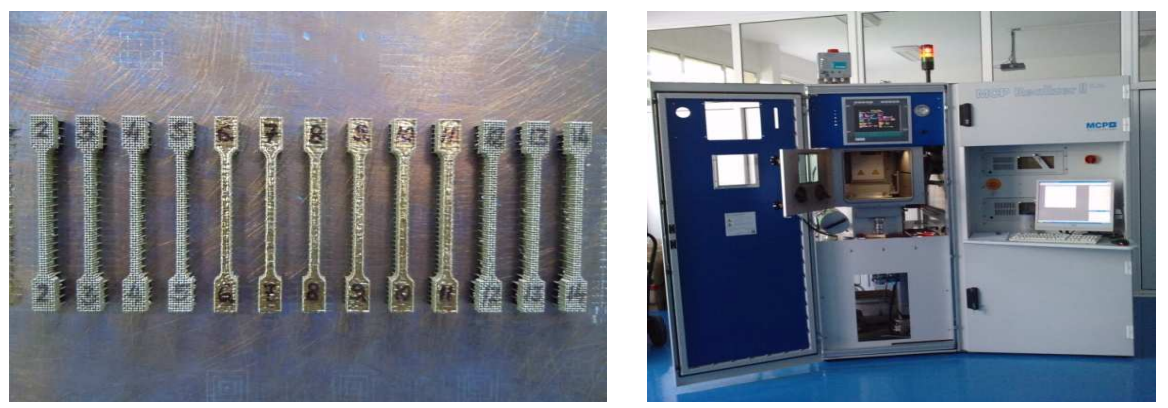

Fig.2. Samples manufactured using the MCP Realizer II SLM 250 machine

The manufactured samples were further on analyzed by using the Scanning Electron Microscope (SEM) JEOL JSM-5600 LV from the Technical University of Cluj-Napoca (TUC-N). By analyzing the images undertaken from the Scanning Electron Microscope, it was easy to observe, by visual inspection that there were differences between the cases when the samples were manufactured with a lens position that was set in an inappropriate way, so as the focus plane was above the platform level of the machine, as compared to the cases when the samples were manufactured with a lens position that was set on the right focus plane, at the platform level of the machine. (see Figure 3).
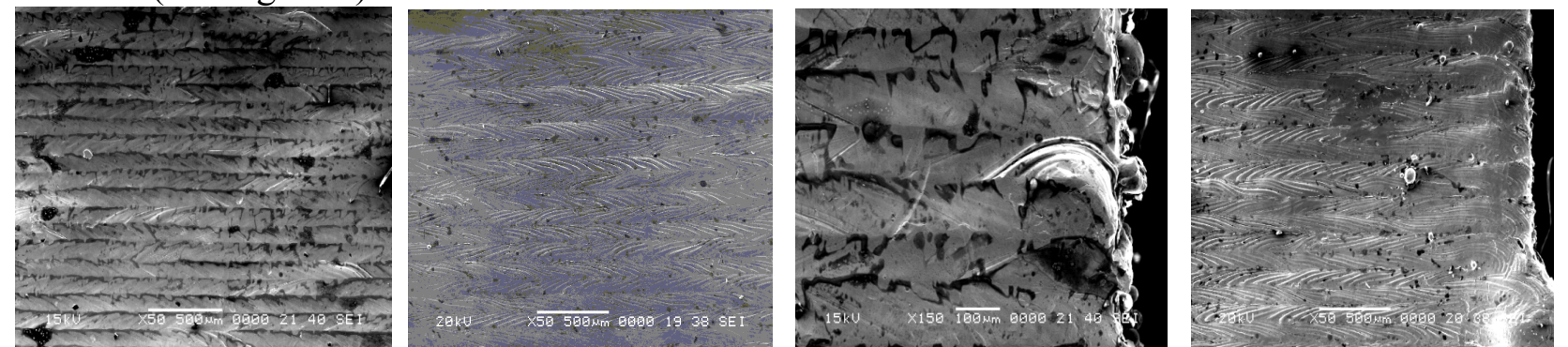

Fig. 3. Welding lines and edges analyzed by SEM in the case when the samples were manufactured outside the focus plane limit and in the in the right focus plane, respectively

The color of the surface and the welding lines appears darker in the first case as compared to the second one, due to the fact that too much energy density has been applied in the first case during the scanning process. The surface quality it is obviously seriously affected in this case, too. The internal defects are more clearly visible, analyzing the samples by SEM with a magnitude of 400x. As it is possible to notice from the images presented in Figure 3, the welding lines are different in the two analyzed cases and the internal structure as well. The internal structure in the first case is filled with cracks and pores that is severely affecting the mechanical properties of the manufactured sample made with this particular lens position adjusted. The sizes of the pores have 10 to $30 \mu \mathrm{m}$ in dimension. The internal structure is an irregularly one, too. By analyzing the sample that it was manufactured within the focus plane limit, it is easy to observe that the welding process during the scanning process it was a compacted one. The pores and the cracks are not so present within the internal structure of the material, which means that the manufactured sample will have a higher strength in this particular analyzed case. In conclusion, as could be observed by the SEM performed analyses, an improper adjustment of the lens position on the SLM machine it might have significantly consequences within the internal structure of the material, with severe consequences over the density of the material, and mechanical resistance of the manufactured part, as well.

\section{Results and discussions}

In order to investigate supplementary the influence of the lens position of the machine, over the material density and porosity within the internal structure, each sample has been weighted by using an analytic balance and the volume of each sample has been determined by using a graduated cylinder, in order to estimate the density of the material. Further on, by using the formulas (1) and (2) it was easy to determine the porosity of each sample that has been manufactured by SLM. The results of the made calculus are presented in detail in Table 3 and Figure 4. 
Table 3. The obtained results

\begin{tabular}{|l|l|l|l|l|l|l|}
\hline $\begin{array}{l}\text { Sample } \\
\text { no. }\end{array}$ & $\begin{array}{l}\mathrm{M} \\
{[\mathrm{g}]}\end{array}$ & $\begin{array}{l}\mathrm{V} \\
{\left[\mathrm{cm}^{3}\right]}\end{array}$ & $\begin{array}{l}\rho_{\mathrm{r}} \\
{\left[\mathrm{g} / \mathrm{cm}^{3}\right]}\end{array}$ & $\begin{array}{l}\mathrm{V}_{0} \\
{\left[\mathrm{~cm}^{3}\right]}\end{array}$ & $\begin{array}{l}\Delta \mathrm{V} \\
{\left[\mathrm{cm}^{3}\right]}\end{array}$ & $\begin{array}{l}\mathrm{P} \\
{[\%]}\end{array}$ \\
\hline 1 & 21.872 & 2.9 & 7.54 & 2.73 & 0.17 & 5.72 \\
\hline 2 & 21.261 & 2.92 & 7.28 & 2.66 & 0.26 & 8.99 \\
\hline 3 & 20.867 & 2.9 & 7.2 & 2.61 & 0.29 & 10.06 \\
\hline 4 & 20.568 & 2.84 & 7.4 & 2.57 & 0.21 & 7.52 \\
\hline 5 & 20.779 & 2.82 & 7.58 & 2.6 & 0.14 & 5.21 \\
\hline 6 & 21.225 & 2.82 & 7.53 & 2.65 & 0.17 & 5.92 \\
\hline 7 & 21.749 & 3 & 7.25 & 2.72 & 0.28 & 9.38 \\
\hline 8 & 21.695 & 2.86 & 7.55 & 2.72 & 0.16 & 5.18 \\
\hline 9 & 21.397 & 2.86 & 7.48 & 2.67 & 0.19 & 6.48 \\
\hline 10 & 22.142 & 2.9 & 7.64 & 2.77 & 0.13 & 4.56 \\
\hline 11 & 22.012 & 2.86 & 7.7 & 2.75 & 0.11 & 3.79 \\
\hline 12 & 21.957 & 2.78 & 7.9 & 2.74 & 0.04 & 1.27 \\
\hline 13 & 21.903 & 2.78 & 7.88 & 2.74 & 0.04 & 1.52 \\
\hline 14 & 21.168 & 2.72 & 7.78 & 2.65 & 0.07 & 2.72 \\
\hline 15 & 22.491 & 2.9 & 7.76 & 2.81 & 0.09 & 3.06 \\
\hline
\end{tabular}

As it is possible to observe from the results presented in Table 3 and Figure 4, there is a maximum value of the porosity as calculated in the case of sample number 3 (the calculated porosity was $10,06[\%]$ ). The minimum value of the porosity as calculated was $1,27[\%]$, in the case of sample number 12 . This fact proves once again that the lens position is obviously very important and is severely influencing the porosity of the material and mechanical resistance of the manufactured part, as well. Actually, the difference between the maximum and minimum value of the porosity was 8,79 [\%]. As related to the density variation presented in Table 3 and Figure 4, the influences are obviously similar. The maximum value of density was obtained (as calculated) in the case of sample number $12\left(\rho=7.90\left[\mathrm{~g} / \mathrm{cm}^{3}\right]\right)$, compared with a minimum value that has been obtained in the case of sample number $3\left(\rho=7.20\left[\mathrm{~g} / \mathrm{cm}^{3}\right]\right.$. This means that there is an important difference remaining, of $0.70\left[\mathrm{~g} / \mathrm{cm}^{3}\right]$, having the same consequence over the mechanical resistance of the manufactured part, at the end.
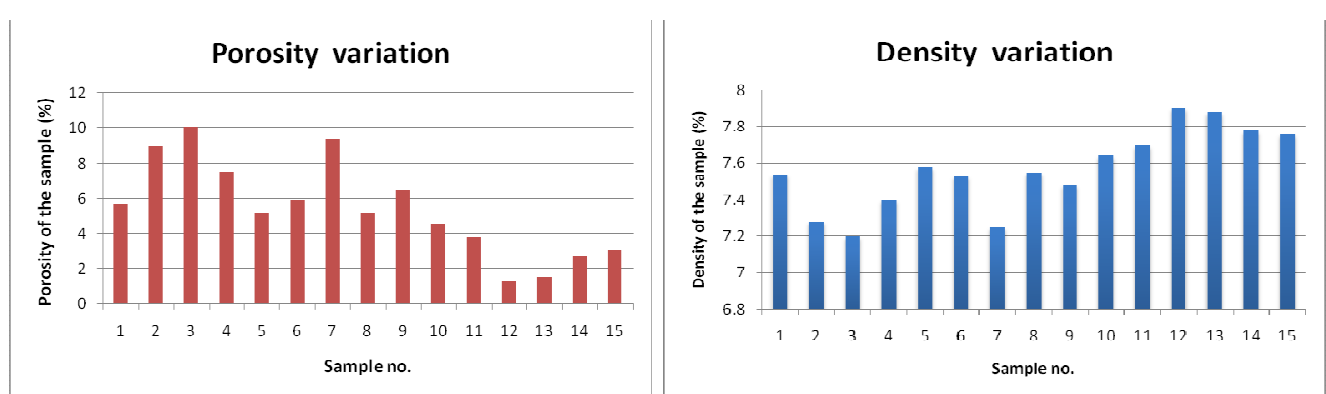

Fig. 4. SLM samples porosity and density variation

In order to analyze the influence of material density over the mechanical resistance of the part (fracture strength of the material), by the theoretical point of view, the sample illustrated in Figure 1 has been considered for the finite element analysis that was made using the LS-DYNA FEA program. Two cases were analyzed within the numerical simulation, one case being considered as for the sample having a density of 7,20 $\left[\mathrm{g} / \mathrm{cm}^{3}\right]$ ) (sample 3, manufactured with a Hatch Solid and Fill Contour Lens Position of $-50[\mu \mathrm{m}]$ ), and a second one, the case of sample number 12, that was manufactured with a Hatch Solid and Fill Contour Lens Position of 40 [ $\mu \mathrm{m}]$, having as experimentally determined, the maximum density value of $7,90\left[\mathrm{~g} / \mathrm{cm}^{3}\right]$. 
As for the made analyses, first of all the mesh has been generated by using the Plate-solid mesh option, which is most indicated for samples made by SLM and then, a set of nodes were established at the ends of the sample in order to design the fixing clamps of the testing machine. The mechanical characteristics of the Stainless Steel 316L material were introduced within the finite element analysis, as they were presented by the producer of the metallic powder within the material datasheet (see Figure 5). The main materials characteristics that were introduced within the FEA analysis were: the materials density (variable), Young's modulus, Poisson's ratio, Yield strength and the elongation of the material [11]. The next step consisted in the design of the actuating law for the clamps of the testing machine. The actuating law of the testing machine clamps is a Displacement/ time type curve. These values were set to zero in the case of fixed clamp on the entire simulation period, and as having a maximum displacement of $10 \mathrm{~mm}$, in the case of the mobile clamp.
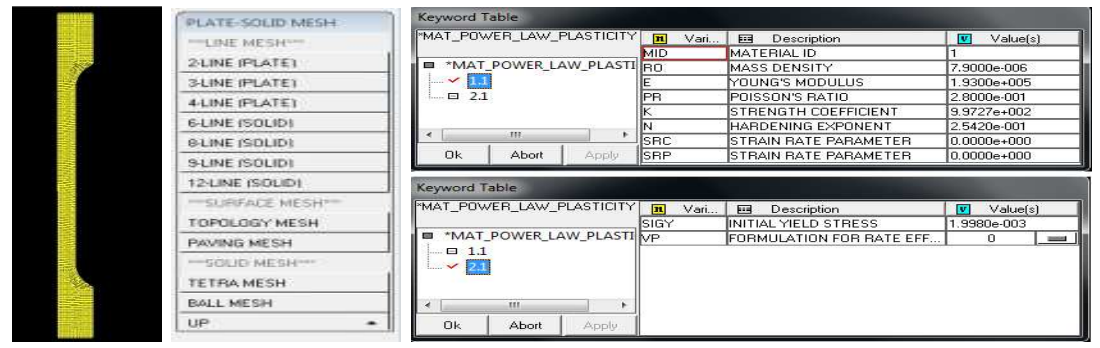

Fig.5. The 3D sketch model generated using the Plate solid mesh-option and material characteristics

The constitutive model that has been considered for the performed analysis was the elastoplastic type with ductile fracture (see formula (3)). It means that the elastic part of the deformation was described using Hooke's law (see formula (4)) that is based mainly on two material characteristics, namely Young's modulus $\left(\mathrm{E}=1.93 * 10^{5}\left[\mathrm{~N} / \mathrm{mm}^{2}\right]\right.$ has been considered for the performed analysis) and Poisson's ratio $(v=0.3$ for the specific case under analysis) and the plastic part of the deformation was described by using the von Misses yield criterion, Swift hardening law, and the associated flow rule, as presented in formulas (5), (6) and (7) :

$$
{ }^{t} \underset{\sim}{\dot{\epsilon}}={ }^{t} \dot{\sim}^{(e)}+{ }^{t} \dot{\sim}^{(p)}, \quad(\forall) t \geq 0,
$$

where: ${ }^{\tau} \underset{\sim}{\dot{E}}-$ is the additive decomposition strain rate tensor; $t \geq 0$ - time, variable during the performed analysis, ${ }^{t} \dot{\sim}^{(e)},{ }^{t} \dot{\sim}^{(p)}$ - elastic and respectively plastic component of tensor ${ }^{t} \dot{\epsilon}$.

$$
{ }^{t} \stackrel{\sim}{(e)}^{(e)}=\frac{1+v}{E}{ }^{t} \underset{\sim}{\sigma}-\frac{v}{E}\left(\operatorname{tr}^{t} \underset{\sim}{\sigma}\right) \underset{\sim}{1}, \quad E>0, \quad 0<v<1 / 2
$$

where: $E$ is Young's modulus; $v$ - Poisson's ratio; ${ }^{t} \underset{\sim}{\sigma}$ - Cauchy stress tensor; $\underset{\sim}{1}$ - unit tensor.

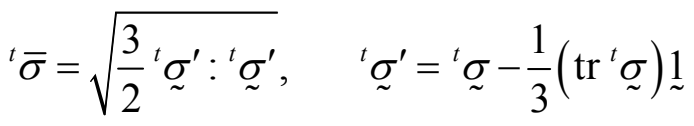

$$
\begin{aligned}
& { }^{t} \bar{\sigma}={ }^{t} Y={ }^{0} Y+H^{t} \bar{\epsilon}^{(p)}, \quad{ }^{0} Y>0, \quad H>0, \quad{ }^{t} \bar{\epsilon}^{(p)} \geq 0, \\
& { }^{t} \dot{\sim}^{(p)}=\frac{3{ }^{t} \bar{\epsilon}^{(p)}}{2^{t} \bar{\sigma}}{ }^{t} \sigma_{\sim}^{\prime}
\end{aligned}
$$

where: ${ }^{t} \bar{\sigma}$ : - is von Mises equivalent stress, ${ }^{0} Y$ - initial yield stress; $H$ - hardening modulus; ${ }^{t} \bar{\epsilon}^{(p)}$ equivalent plastic strain. 
Finally, in order to run the simulations, the ETA Femb Post-Processing module of the LSDYNA program has been used.

There is at least one important conclusion that could be stated by analyzing the results obtained from the numerical simulations that were made in the case of sample 3 , having a density of 7,20 $\left[\mathrm{g} / \mathrm{cm}^{3}\right]$ as compared with the case of sample 12 , having a density of $7,90\left[\mathrm{~g} / \mathrm{cm}^{3}\right]$. As stated by the numerical results presented in Figure 6, basically there is a difference between the material fracture strength, as estimated in these analyzed cases $\left(\sigma_{\mathrm{r}}=630\left[\mathrm{~N} / \mathrm{mm}^{2}\right]\right.$ - in the case of sample 12, as compared to $564\left[\mathrm{~N} / \mathrm{mm}^{2}\right]$ - in case of sample 3). This means that there is a significant total difference of approximately 10,5 [\%], between fracture strength obtained in the case of sample 3 and 12 , with obviously important consequences over the mechanical resistance of the metallic parts made by SLM with the machine working at the particular lens position of sample $3(-50[\mu \mathrm{m}])$.
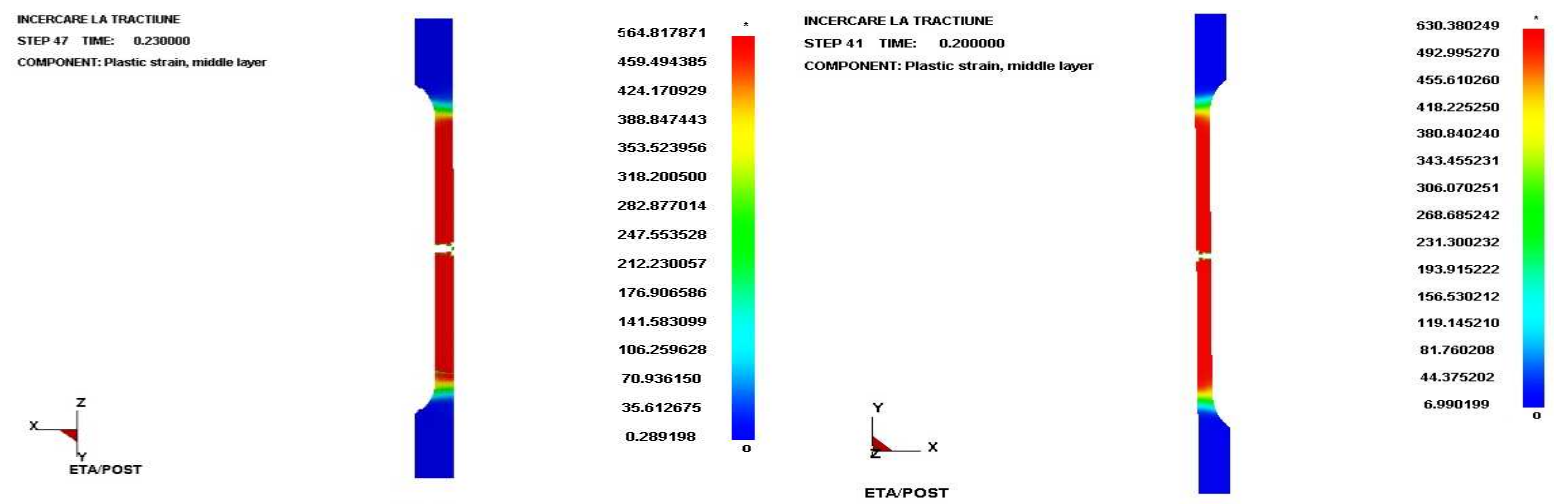

Fig. 6. Fracture strength of the analyzed samples within LS-DYNA FEA (the cases of samples 3 and 12 , having a density of $7,20\left[\mathrm{~g} / \mathrm{cm}^{3}\right]$ and $7,90\left[\mathrm{~g} / \mathrm{cm}^{3}\right]$, respectively

The results obtained by numerical simulation were comparable with the ones obtained by the fracture strength experiment that was performed, using the Galdabini testing machine presented in Figure 7. The minimum fracture strength value was experimentally determined also in the case of sample $3\left(\sigma_{\mathrm{r}}=562\left[\mathrm{~N} / \mathrm{mm}^{2}\right]\right)$, as compared to $564\left[\mathrm{~N} / \mathrm{mm}^{2}\right]$, value obtained with LS-DYNA program. The maximum obtained value was $621.5\left[\mathrm{~N} / \mathrm{mm}^{2}\right]$ in the case of sample 12, as compared with $630\left[\mathrm{~N} / \mathrm{mm}^{2}\right]$, value that has been obtained within the numerical simulation made with LSDYNA. In conclusion, by the experimental point of view, there is a difference between the minimum and the maximum value of 9,5 [\%], which is comparable with the theoretically difference obtained by simulation made using LS-DYNA FEA program $(10,5[\%])$. This fact has proved once again if it still was necessary, that if the machine is running with an inappropriate lens position adjustment, the mechanical resistance of the manufactured part will be significantly decreased. This is the reason why adjusting the correct lens position of the SLM machine it is critically important.
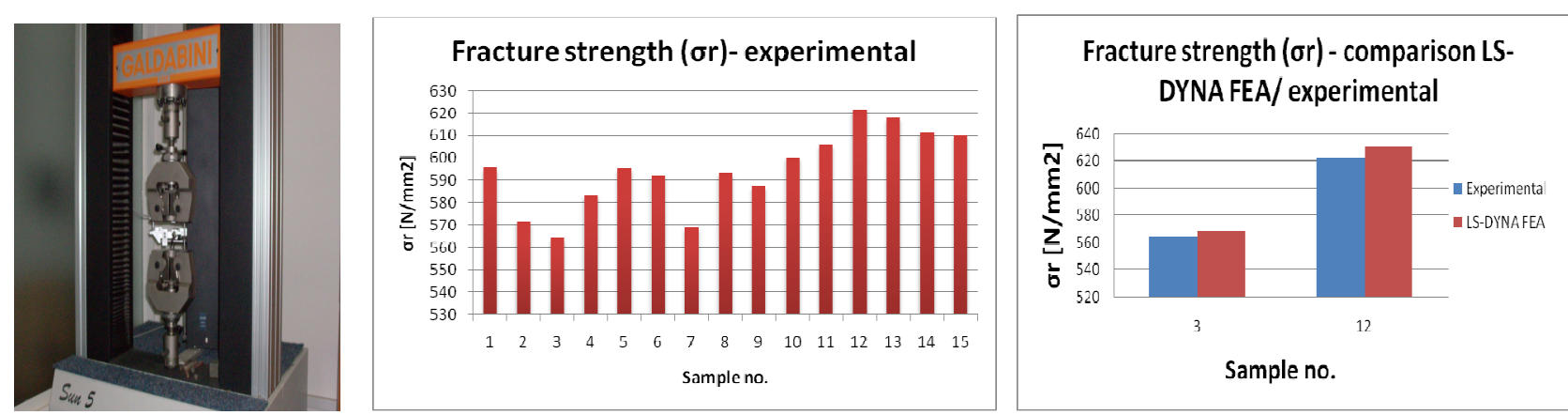

Fig. 7. Fracture strength determined with Galdabini equipment from the Technical University of Cluj-Napoca (TUC-N); Theoretical and experimental comparisons in case of sample 3 and 12. 


\section{Conclusions}

In conclusion of presented research, it is important to notice that the lens position plays an important role regarding the influence of the material structure of metallic parts made by SLM, as demonstrated by the SEM analysis that were performed. Not only material structure is severely influenced, but the mechanical characteristics, such as the fracture strength, as well. From the set of 15 samples that were manufactured, by using the SLM machine, the sample number 12 has corresponded by the mechanical resistance point of view, so the lens position has finally been adjusted with a value of $+40[\mu \mathrm{m}]$, as compared to the starting position (the initial position that has been considered as reference at starting point of the experiment). Finite element method and experimental tests were successfully used in order to estimate how density variation is influencing the fracture strength of the metallic parts made by Stainless Steel 316L material, using different lens positions within the optical system of the SLM machine. It has been concluded that by decreasing the density of the material from a value of $7,90\left[\mathrm{~g} / \mathrm{cm}^{3}\right]$ (in the case of sample 12 manufactured with a value of lens position adjusted at $+40[\mu \mathrm{m}]$ ) to a value of $7,20\left[\mathrm{~g} / \mathrm{cm}^{3}\right]$ (in the case of sample 3 , manufactured with a value of lens position adjusted to $-50[\mu \mathrm{m}])$, the fracture strength will be decreased with a significantly value up to $10,5[\%]$, mainly due to the remained pores into the internal structure of the material.

\section{Acknowledgment}

This paper was supported by the project "Development and support of multidisciplinary postdoctoral programmes in major technical areas of national strategy of Research Development Innovation" 4D-POSTDOC, contract no. POSDRU/89/1.5/S/52603, project co-funded by the European Social Fund through Sectoral Operational Programme Human Resources Development 2007-2013"

\section{References}

[1] W. Steen, J. Mazumder, Laser Material Processing, pg. 367, University of Michigan, Springer, 2010.

[2] E.C. Santos, M., Shiomi, K., Osakada, T., Laoui, Rapid Manufacturing of Metal Components by Laser Forming, Int. J. of Machine Tools Manufacturing, 46, No. 12-14, (2006) 1459-1468.

[3] L. Morovič, P. Pokorný, Optical 3D Scanning of Small Parts. Advanced, Materials Research Trans Tech Publications, Switzerland Vols. 468-471, (2012) 2269-2273.

[4] Z. Wenxian, S.Yusheng, L. Bing, X. Lin, J. Wei, Consecutive Sub-Sector Scan Mode With Adjustable Scan Lengths for Selective laser Melting Technology, International Journal of Advance Manufacturing Technology 41 (2009) 706-713.

[5] M. Badrossamay, E. Yasa, Vaerenbergh Van J., J.-P. Kruth, Improving Productivity Rate in SLM of Commercial Steel Powders, Proceedings of RAPID 2009 Conference, May 12-14, Schaumburg, IL, USA, 2009.

[6] L. Castillo, Study About the Rapid Manufacturing of Complex Parts of Stainless Steel and Titanium, Instituto Tecnologico Metalmecanico, Valencia, (2005)

[7] I. Gibson, D. W. Rosen, B. Stucker, Additive Manufacturing Technologies: Rapid Prototyping to Direct Digital Manufacturing, Springer, National University of Singapore, (2009).

[8] M. Groover, Fundamentals of Modern Manufacturing: Materials, Processes and Systems, pg. 788, USA (2010).

[9] Y. Wang, Y. Shen, Z. Wang, J. Yang, N. Liu, W. Huang, Development of Highly Porous Titanium Scaffolds by Selective Laser Melting, Materials Letters 64 (2010) 674-676.

[10] I. Tolosa, F. Garciandia, F. Zubiri. F. Zapirian, A. Esnaola, Study of mechanical properties of AISI 316 stainless steel processed by "selective laser melting", following different manufacturing strategies, Int. J. of Adv. Manuf. Tech., Vol. 51, Issue 5-8, (2010), 639-647.

[11] Information on http://www.slm-solutions.com/cms/upload/pdf/SLM-Material.pdf 